\title{
Prevalence of $G J B 2$ gene mutations correlated to presence of clinical and environmental risk factors in the etiology of congenital sensorineural hearing loss of the Romanian population
}

\author{
ALEXANDRA NEAGU ${ }^{1 *}$, ADELA-IOANA MOCANU ${ }^{2}$, ALEXANDRU BONCIU $^{3}$, \\ GABRIELLA COADA $\breve{4}^{4}$ and HORIA MOCANU ${ }^{*}$ \\ ${ }^{1}$ Department of ENT\&HNS, 'Marie S. Curie' Emergency Children Hospital Bucharest, 041434 Bucharest; \\ ${ }^{2}$ Department of ENT\&HNS, Bucharest Emergency University Hospital, 050098 Bucharest; \\ ${ }^{3}$ Department of ENT\&HNS, 'Dr. Carol Davila' Central Military Emergency University Hospital, \\ 010825 Bucharest; ${ }^{4}$ Department of ENT\&HNS, 'Sfânta Maria' Clinical Hospital, 011172 Bucharest; \\ ${ }^{5}$ Department of ENT\&HNS, Faculty of Medicine, 'Titu Maiorescu' University, 031593 Bucharest, Romania
}

Received January 20, 2021; Accepted February 19, 2021

DOI: $10.3892 / \mathrm{etm} .2021 .10044$

\begin{abstract}
Although etiologically heterogeneous at least $50 \%$ of all early on-set hearing losses have a genetic cause and of these, the large majority, $75-80 \%$ are most probably autosomal recessive and $70 \%$ are non-syndromic. The rest of the congenital hearing losses are determined by clinical and environmental factors such as ototoxic medication, prematurity, and complications at birth. During the last decade it became clear that $50-80 \%$ of all such afflictions result from mutations in a single gene, GJB2, which encodes the protein Connexin 26. In order to, at least partially clarify this problem, especially in an emerging country such as Romania, where the problem is not studied adequately, we developed a comprehensive study of genetic, clinical and environmental risk factors for congenital hearing loss. The two most common variations of this gene, $35 \mathrm{del} G$ and $W 24 \mathrm{X}$ in children with positive diagnosis of bilateral severe to profound sensorineural hearing loss were investigated. A cohort of 34 children (20 female and 14 male), ages between 2 and 10 (mean age 4.62 years), coming from 33 non-related families were evaluated. All cases were diagnosed with severe or profound bilateral congenital SNHL. A statistical comparison of genetic and environmental/clinical prevalence was also attempted since the presence of a genetic disorder cannot rule out the role of other documented risk factors in the etiology of SNHL. The results showed that,
\end{abstract}

Correspondence to: Dr Horia Mocanu, Department of ENT\&HNS, Faculty of Medicine, 'Titu Maiorescu' University, Street Gheorghe Petraşcu 67A, 031593 Bucharest, Romania

E-mail: horia.mocanu@prof.utm.ro

*Contributed equally

Key words: Connexin Cx26, GJB2, sensorineural hearing loss, DNA mutational analysis, risk factors, environment, gene frequency
$29.4 \%$ of cases (10/34) were homozygotic for the $35 \mathrm{del} G$ mutation $35 \mathrm{delG} / 35 \mathrm{del} G$ ), also known as genotype $\Delta / \Delta .5 .88 \%$ of cases (2/34) belong to the heterozygotic bi-genic group $35 \mathrm{del} / \mathrm{W} 24 X$. The clinical factors with high statistical significance for SNHL in a non-genetic group have no significance for genetic SNHL patients. Thus, the present study confirms the relatively high prevalence of the $35 \mathrm{delG}$ and $\mathrm{W} 24 \mathrm{X}$ mutations in cases of congenital non-syndromic severe of profound bilateral SNHL.

\section{Introduction}

According to data reported by the World Health Organization, over 250 million individuals currently suffer from hearing loss of variable etiology, which represents $4.2 \%$ of the world's population (1-5). Congenital hearing loss is relatively frequent, with a prevalence reported by different sources in literature as varying between 1-3/1000 newborns (6) and 1/500 newborns (7).

Due to the etiological heterogeneity of congenital hearing loss, genetic, clinical and environmental risk factors often combine and provide a very complex picture that makes genetic evaluation and council extremely difficult, especially for very small children. Recent findings indicate the mutations of the GJB2 and GJB6 genes on the 13q11-q12 chromosome as responsible for more than $50 \%$ of all types of non-syndromic autosomal recessive congenital hearing loss in certain populations. This information facilitates, to some extent, the genetic diagnosis and gives families increased information regarding this genetic affliction. Although some hearing losses can be diagnosed with certainty as having a genetic cause, the presence of other risk factors such as ototoxic medication, prematurity, and complications at birth cannot be ruled out and the statistical significance of combined genetic and environmental factors represents an important but very little studied issue (5-7).

The GJB2 and GJB6 genes encode the Connexin 26 (Cx26) and Connexin 30 (Cx30) membrane proteins which form the 
intercellular heteromeric channels known as gap-junctions. These structures have an important role in the cochlea homeostasis and ensure the influx of potassium ions from the internal and external hair cells to the cochlea supporting cells. The GJB2 gene has over 100 alleles, especially for the autosomal recessive forms of deafness. The deletion of a single guanine, $35 \mathrm{del} G$, is responsible for over $50 \%$ of the non-syndromic sensorineural hearing loss (SNHL) in Europe, North America and Asia (8,9). The common deletion 342-Kb of the GJB6 gene (GJB6-D13S1830) appears in up to $20 \%$ of all SNHL cases in the US and could be responsible of approximately $10 \%$ of all the DFNB1 alleles, since it has a very wide action range, based on ethnic origin and is frequently associated with the $35 \mathrm{delG} / \mathrm{GJB} 2$ mutation $(8,10,11)$.

Recent findings have shown that the GJB6 mutations have no active role in the etiology of congenital non-syndromic SNHL and that the Connexin 30 protein would only modulate the action of the Connexin 26 protein. This would mean that in the case of an SNHL with a GJB6 deletion, the deafness would be, in fact, the result of a GJB2 deletion modulated by the presence of the GJB6 deletion (12).

\section{Materials and methods}

Subjects. A cohort of 34 children (20 female and 14 male), ages between 2 and 10 (mean age 4.62 years), coming from 33 non-related families was evaluated. All cases were diagnosed with severe or profound bilateral congenital SNHL, over a time span of 3 years. After establishing a complete family and personal history, the patients underwent a thorough ENT examination which excluded the syndromic forms of deafness and other associated diseases. A personal interview of the parents provided essential information regarding the pregnancy period (mother's health, pollution, use of ototoxic drugs, alcohol, smoking during pregnancy), birth (premature child, hypoxia, cranial trauma, extended ICU care after birth $>5$ days) and evolution of the SNHL (when and how it was discovered).

Methods. After excluding any middle ear pathology, the audiological diagnosis was established by using otoacoustic emissions (OAE), brainstem auditory evoked response (BAER) and auditory steady state response (ASSR) for children under 4 years of age (following the current international guidelines-Year 2007 Position Statement: Principles and Guidelines for Early Hearing Detection and Intervention Programs: Joint Committee on Infant Hearing) and Pure Tone Audiometry for children over 4 years of age. Syndromic or acquired hypoacusis were excluded from the study. Patients with a suggestive SNHL family history (deaf parents) were also excluded but patients with suggestive risk factors (ototoxic treatments, hypoxia at birth, and prematurity) were included, since it has been shown that the presence of such factors does not exclude a genetic etiology of the SNHL. A statistical correlation between the presence of these risk factors and a genetic SNHL was calculated and compared to another that only took into consideration the statistical significance of the clinical and environmental factors on a much larger cohort of newborns.

None of the patients benefited from neonatal screening even though some of them presented obvious risk factors for congenital SNHL. The mean age for diagnosis was 2.7 years.
$D N A$ and $A S-P C R$. After obtaining the informed, written consent of the parents, a blood sample was taken for molecular testing and establishing a possible genetic cause for hearing loss. Peripheral blood (3 ml) was collected in EDTA tubes (ethylenediaminetetraacetic acid) from each participant by venous puncture.

DNA was extracted from peripheral blood leukocytes using the commercially available kit QIAmp DNA Minikit (Qiagen $\mathrm{GmbH}$ ), using the following protocol: Electrophoresis $1.5 \%$ agarose gel in $1 \mathrm{X}$ TAE, $80-100 \mathrm{~V}$; DNA control $=\lambda$ DNA standard; Samples $=7 \mu 1$ DNA $+3 \mu 1$ LB (Luria broth); Control $=5 \mu \mathrm{l} \lambda \mathrm{DNA}+3 \mu \mathrm{l} \mathrm{LB}$. The cultures were stopped with colchicine during the metaphase. The DreamTaq DNA polymerase from ThermoScientific DreamTaq Green PCR Master Mix (2X) was used. The reactants for the PCR reaction are presented in Table I. The molecular analysis was carried out using AS-PCR and multiplex-PCR techniques by directly amplifying the DNA with specific primers. Sequences of the forward and reverse primers $(\rightarrow$, direction) are: Forward primer 5'-TCTTTTCCAGAGCAAACCGC-3'; Reverse primer 5'-GCTGGTGGAGTGTTTGTTCACACCCGC-3'. For W24X mutation, 5'-AAGGTGACCAAGTTCATGCTCATGCTA AATGAAGAGGACGGTGAGCT-3' detected the mutations and 5'-CGCCCAGAGTAGAAGATGGATT-3' served as the common reverse primer.

After thawing the DreamTaq Green PCR Master Mix (2X), gently vortexing and briefly centrifuging, the amplification program was carried out as follows: Initial denaturation at $95^{\circ} \mathrm{C}$ for $3 \mathrm{~min}$, followed by 30 cycles, each comprising denaturation at $94^{\circ} \mathrm{C}$ for $40 \mathrm{sec}$, annealing at $65^{\circ} \mathrm{C}$ for $60 \mathrm{sec}$, extension at $72^{\circ} \mathrm{C}$ for $60 \mathrm{sec}$ and a final extension at $72^{\circ} \mathrm{C}$ for 7 min.

PCR products were submitted to a $2.5 \%$ agarose gel electrophoresis, stained with $1 \mu 1$ ethidium bromide and visualised under a UV light transilluminator. Weight marker $100 \mathrm{pb}$ was calculated as $6 \mu \mathrm{l}$ Marker (GeneRuler 100 bp DNA ladder) + 2 LB (6X DNA Loading Dye)

The $89 \mathrm{bp}$ resulted as PCR products of amplification were digested at $37^{\circ} \mathrm{C}$ with $B s t \mathrm{NI}$ restriction enzyme (New England Biolabs Inc.). In absence of deletion, the enzyme breaks occurred as 2 fragments, 69 and 20 bp. If deletion was present, the enzyme did not break the DNA sequence ( $89 \mathrm{bp}$ ).

Statistical analysis. After asserting the genetic etiology of the SNHL for all cases, the results were correlated to the presence of other risk factors in the patient's history. All data regarding the newborns (NBs) and the risk factors were centralized in a Microsoft Excel database and were attributed codes for easy statistical analysis. Statistical analysis was carried out using the Excel and SPSS ver. 15.00 programs. The data were synthesized as percentages, means, mean \pm standard deviations and quartiles. The statistical significance level used was $\mathrm{P} \leq 0.05$. The data were analyzed in relation to the presence of environmental and clinical risk factors. For quantity variables, according to data distribution, parametric (Student's t-test) and non-parametric tests (Mann-Whitney) were applied whereas for quality variables, proportion equality tests (Fisher's exact and Likelihood Ratio) were applied.

In order to identify the significant risk factors, the univariate logistic regression was initially used, by calculating the odds 
Table I. Reactants of the PCR reaction.

\begin{tabular}{lcc}
\hline Substance & 1X (X=number of samples $)$ & $34 \mathrm{X}$ \\
\hline Master Mix 2X & $12.5 \mu 1$ & $425 \mu 1$ \\
Forward Primer-Oligo 1 & $2.5 \mu 1$ & $85 \mu 1$ \\
Reverse Primer-Oligo 2 & $2.5 \mu 1$ & $85 \mu 1$ \\
Water, nuclease free & $6 \mu 1$ & $204 \mu 1$ \\
Total & $23.5 \mu 1$ & $799 \mu 1$ \\
\hline
\end{tabular}

ratio (OR) together with the $95 \%$ confidence interval and then the multivariate logistic regression including all variables and using a Forward Stepwise (Wald) selection percentage of variables.

The results of this statistical study were then compared to those of a similar study performed on 854 patients that were screened for congenital SNHL but had no proven genetic etiologic involvement. The aim was to determine whether the known environmental risk factors have the same statistical significance in genetic cases.

\section{Results and Discussion}

Since genetic testing is an expensive method and the financial means of the study were limited, a selection of patients was necessary. From the initially evaluated cohort of 58 cases with severe or profound bilateral SNHL, only 34 cases were selected: Children that had no other health issues (non-syndromic cases) and had no family history of SNHL (normal hearing parents). The 34 subjects underwent a genetic screening for the $35 \mathrm{del} G$ and $W 24 X$ mutations of the GJB2 gene.

The results showed that, $29.4 \%$ of cases (10/34) were homozygotic for the $35 \mathrm{del} G$ mutation $(35 \mathrm{del} G / 35 \mathrm{del} G$ ), also known as genotype $\Delta / \Delta$ (the Greek letter $\Delta$ preceding the name of a gene, signifies that the gene has a chromosome deletion while the letter $\mathrm{N}$ represents the lack of a deletion). No case of heterozygosity $35 \mathrm{del} / N(\Delta / \mathrm{N})$ was present for the 35 del $G$ mutation while $5.88 \%$ of cases $(2 / 34)$ belong to the heterozygotic bi-genic group $35 \mathrm{delG} / \mathrm{W} 24 \mathrm{X}$.

The $W 24 X$ mutation was present in $5.88 \%$ of cases $(2 / 34)$ as homozygotic genotype (W24X/W24X) and in $2.94 \%$ of cases $(1 / 34)$ as heterozygotic genotype $(W 24 X / N)$. Results are presented in Table II. The overall prevalence of the mutant allele was $32.35 \%$ for $35 \mathrm{del}$ and $10.29 \%$ for the $W 24 X$.

As far as environmental factors are concerned, the urban environment becomes statistically significant $(\mathrm{P}=0.027)$ for SNHL with genetic etiology compared to the patients with non-genetic etiology but that could also be attributed to the small number of cases included in the study. Other known environmental risk factors such as prematurity $(\mathrm{P}=0.042)$, age of the mother $(\mathrm{P}=0.048)$, ototoxic medication during pregnancy $(\mathrm{P}=0.023)$ also have great statistical significance for genetic SNHL (Table III).

The clinical factors with high statistical significance for SNHL in a non-genetic group have no significance for genetic SNHL patients (Table III). The statistical values included in this table were specifically calculated for genetically diagnosed patients (35delG and W24X mutations) with the
Table II. Results of genetic testing in the present study.

\begin{tabular}{lc}
\hline Genotype & No. of subjects/total no. of patients $(\%)$ \\
\hline 35delG/35delG & $10 / 34(29.4)$ \\
35delG/N & $0 / 34(0)$ \\
35delG/W24X & $2 / 34(5.88)$ \\
W24X/W24X & $2 / 34(5.88)$ \\
W24X/N & $1 / 34(2.94)$ \\
N/N & $19 / 34(55.88)$
\end{tabular}

$\mathrm{N}$, absence of mutation (35delG or W24X).

purpose of demonstrating that sometimes, the presence of a genetic mutation can be statistically correlated to the presence of known environmental factors that also generate SNHL (i.e. prematurity, urban environment, and ototoxic medication).

SNHL is one of the most frequent human disabilities and the genetic factor plays a central role in its research and diagnosis. Over 130 loci for human non-syndromic SNHL have been identified and it is estimated that more than 100 mutations of the Cx26 encoding genes may be involved (13). This variety of mutation makes the genetic diagnosis extremely difficult and even more, the prevalence of certain genes varies for different population groups.

The $35 \mathrm{del} G$ mutation of the GJB2 gene remains, however, the main cause of genetic SNHL in the Caucasian population. The prevalence of mutation carriers varies from 1/35 for the south European population to 1/79 in Northern Europe $(14,15)$. The maximum prevalence is recorded in countries around the Mediterranean (13). This mutation also has one of the highest pathogenic potential in humans, with a frequency of carriers similar to that of the deltaF508 mutation of the cystic fibrosis gene $(C F T R)(14,16)$. It can be found both in homozygosis and heterozygosis state and it can also be associated to other mutations of the GJB2 gene or the GJB6 gene such as D13S1830, which is the second-ranking mutation involved in the etiology of SNHL in Europe. In certain population groups such as the Japanese, the Chinese, Ashkenazi Jews and the Roma populations, the $35 \mathrm{del} G$ mutation is very rare and is replaced by other mutations such as $235 \mathrm{delC}$, 167delT or W24X (17).

The present study evaluated the prevalence of the $35 \mathrm{del} G$ and $W 24 X$ mutations within the Romanian population suffering from congenital non-syndromic SNHL and attempted to associate the presence of the genetic mutation to other known risk factors for SNHL. Although the number of studied cases was relatively small and all diagnosed in the same clinic, the results showed that the screening for known mutations and a rigorous selection of cases can pinpoint the presence of the genetic factor in almost $50 \%$ of cases of severe or profound congenital SNHL.

The prevalence of the $35 \mathrm{del} G$ mutation among the deaf patients was $29.4 \%$ in accordance with similar studies that reported $13.6 \%$ in Jordan, $14 \%$ in Palestine $(13,18), 16 \%$ in Egypt $(13,19), 5.66 \%$ in Iran $(12,13)$ but lower than other studies that report $94 \%$ in Lebanon $(13,20)$ and $60-80 \%$ in European populations $(13,21)$ (Table IV). The relative frequency of the 35 delG mutant alleles was also in line with previously 
Table III. Statistical comparison of environmental and clinical factors for genetic and non-genetic SNHL.

Cohort

\begin{tabular}{|c|c|c|c|}
\hline \multirow[b]{2}{*}{ Risk factors } & & \multirow[b]{2}{*}{ P-value (test) } \\
\hline & Screening $(\mathrm{N}=854)$ & Genetic $(\mathrm{N}=34)$ & \\
\hline Gender=Female & $432 / 854(50.6 \%)$ & $20 / 34(58.8 \%)$ & 0.384943 (Fisher exact) \\
\hline Environment=Urban & $563 / 852(66.1 \%)$ & $16 / 34(47.1 \%)$ & 0.027233 (Fisher exact) \\
\hline Prematurity $=$ Yes & $115 / 854(13.5 \%)$ & $9 / 34(26.5 \%)$ & 0.042056 (Fisher exact) \\
\hline Gestational age & $39[38.00,39.00]$ & $38[36.00,40.00]$ & 0.138 (Mann-Whitney) \\
\hline Apgar score & $8.38 \pm 0.8694$ & $8.41 \pm 0.9883$ & $0.826370($ Student T) \\
\hline Mother's age & $28.84 \pm 5.951$ & $26.79 \pm 4.841$ & 0.048529 (Student T) \\
\hline Maternal pathologies $=$ Yes & $164 / 854(19.2 \%)$ & $9 / 34(26.5 \%)$ & 0.275933 (Fisher exact) \\
\hline Chemicals, Radiation=Yes & $1 / 854(0.1 \%)$ & $0 / 34(0.0 \%)$ & 1.000000 (Fisher exact) \\
\hline Ototoxic medication for mother=Yes & $88 / 854(10.3 \%)$ & $8 / 34(23.5 \%)$ & 0.023347 (Fisher exact) \\
\hline Birth complications $=$ Yes & $50 / 854(5.9 \%)$ & $3 / 34(8.8 \%)$ & 0.449632 (Fisher exact) \\
\hline Congenital infections $=$ Yes & $110 / 854(12.9 \%)$ & $3 / 34(8.8 \%)$ & 0.608554 (Fisher exact) \\
\hline Periintraventricular hemorrhage $=$ Yes & $22 / 854(2.6 \%)$ & $1 / 34(2.9 \%)$ & 0.597264 (Fisher exact) \\
\hline Respiratory distress $=$ Yes & $46 / 854(5.4 \%)$ & $3 / 34(8.8 \%)$ & 0.427561 (Fisher exact) \\
\hline Perinatal hypoxia=Yes & $98 / 854(11.5 \%)$ & $4 / 34(11.8 \%)$ & 1.000000 (Fisher exact) \\
\hline Mechanical ventilation=Yes & $81 / 854(9.5 \%)$ & $4 / 34(11.8 \%)$ & 0.558063 (Fisher exact) \\
\hline Neonatal Intensive Care (NICU)=Yes & $78 / 854(9.1 \%)$ & $4 / 34(11.8 \%)$ & 0.545578 (Fisher exact) \\
\hline Neonatal hypotension=Yes & $37 / 854(4.3 \%)$ & $0 / 34(0.0 \%)$ & 0.393117 (Fisher exact) \\
\hline Hypoxic ischemic encephalopathy (HIEP),=Yes & $3 / 853(0.4 \%)$ & $0 / 34(0.0 \%)$ & 1.000000 (Fisher exact) \\
\hline Hyperbilirubinemia=Yes & $135 / 854(15.8 \%)$ & $3 / 34(0.0 \%)$ & 0.341235 (Fisher exact) \\
\hline Cranial trauma $=$ Yes & $56 / 854(6.6 \%)$ & $0 / 34(0.0 \%)$ & 0.265235 (Fisher exact) \\
\hline Ototoxic medication for $\mathrm{NB}=$ Yes & $64 / 854(7.5 \%)$ & $5 / 34(14.7 \%)$ & 0.176912 (Fisher exact) \\
\hline Craniofacial abnormalities=Yes & $1 / 854(0.1 \%)$ & $0 / 34(0.0 \%)$ & 1.000000 (Fisher exact) \\
\hline Other abnormalities $=$ Yes & $91 / 853(10.7 \%)$ & $4 / 34(11.8 \%)$ & 0.777523 (Fisher exact) \\
\hline Very Low Birth Weight (VLBW) & $18 / 854(2.1 \%)$ & $0 / 34(0.0 \%)$ & 1.000000 (Fisher exact) \\
\hline Extremely Low Birth Weight (ELBW) & $8 / 854(0.9 \%)$ & $0 / 34(0.0 \%)$ & 1.000000 (Fisher exact) \\
\hline
\end{tabular}

published studies (Table V). Extensive research conducted in the Middle East determined that the frequent presence of the $35 \mathrm{del} G$ mutation is directly linked to the high level of consanguinity of the studied populations, which does not apply to the European and therefore the Romanian population.

The frequency of the $35 \mathrm{delG}$ mutation carriers varies in different studies from $1.1 \%$ in Jordan to $1.66 \%$ in Syria and up to $3.2 \%$ in Italy, the highest known frequency thus far (13).

Concerning the presence of the homozygotic genotype $35 \mathrm{delG} / 35 \mathrm{delG}$ in the Romanian population, the study is in accordance with those of other Romanian researchers from different areas such as: Bucharest (36\%), Craiova (24\%) and Transylvania (25.33\%) (22-24) (Table VI). A particular feature of the results is the total absence of the heterozygotic genotype, $35 \mathrm{delG} / \mathrm{N}$. This result had been reported only once before by Romanian researchers, in a 2010 study by Lazăr et al on 75 patients from Transylvania (22).

The results of the present study suggest that the high prevalence of the $35 \mathrm{del} G$ mutation within the studied population may represent enough reasons to implement genetic diagnosis and council on a larger scale and also continue the research on this subject. However, the techniques used for detecting mutations are very expensive and occasionally prone to sequencing errors (14).
The $W 24 X$ mutation is another relatively common cause for the non-syndromic SNHL, especially in populations from Northern and Southern India $(13,25,26)$. A study on the Roma population of Slovakia reports a relatively large prevalence of $W 24 X$ carriers $(26.1 \%)$, probably in close correlation to the Indian origin of these populations. The present study found a $10.29 \%$ prevalence of the homozygotic genotype $(W 24 X / W 24 X)$ and a $5.88 \%$ prevalence of the digenic heterozygotic genotype $(35 \mathrm{delG} / \mathrm{W} 24 \mathrm{X})$ for this mutation, similar to another Romanian study by Lazăr et al which reported a $1.33 \%$ prevalence for the $W 24 X / W 24 X$ genotype and a $2.66 \%$ prevalence for the $35 \mathrm{delG} / W 24 X$ genotype (22) (Table VI).

The diagnosis of SNHL in children is very complex and requires a number of specialized tests for establishing the etiology (27). However, testing for GJB2 mutations is currently recommended as an initial test, followed by GJB6 testing in the case of a negative result (28). Genetic testing has become a very useful tool for the ENT specialist in the attempt to explain the etiology of the SNHL. The main benefit of genetic testing is that it can explain deafness without any additional examinations (29). Additionally, information can be obtained regarding the manner in which the mutation was transmitted and the probability of appearance in other possible offspring $(29,30)$. 

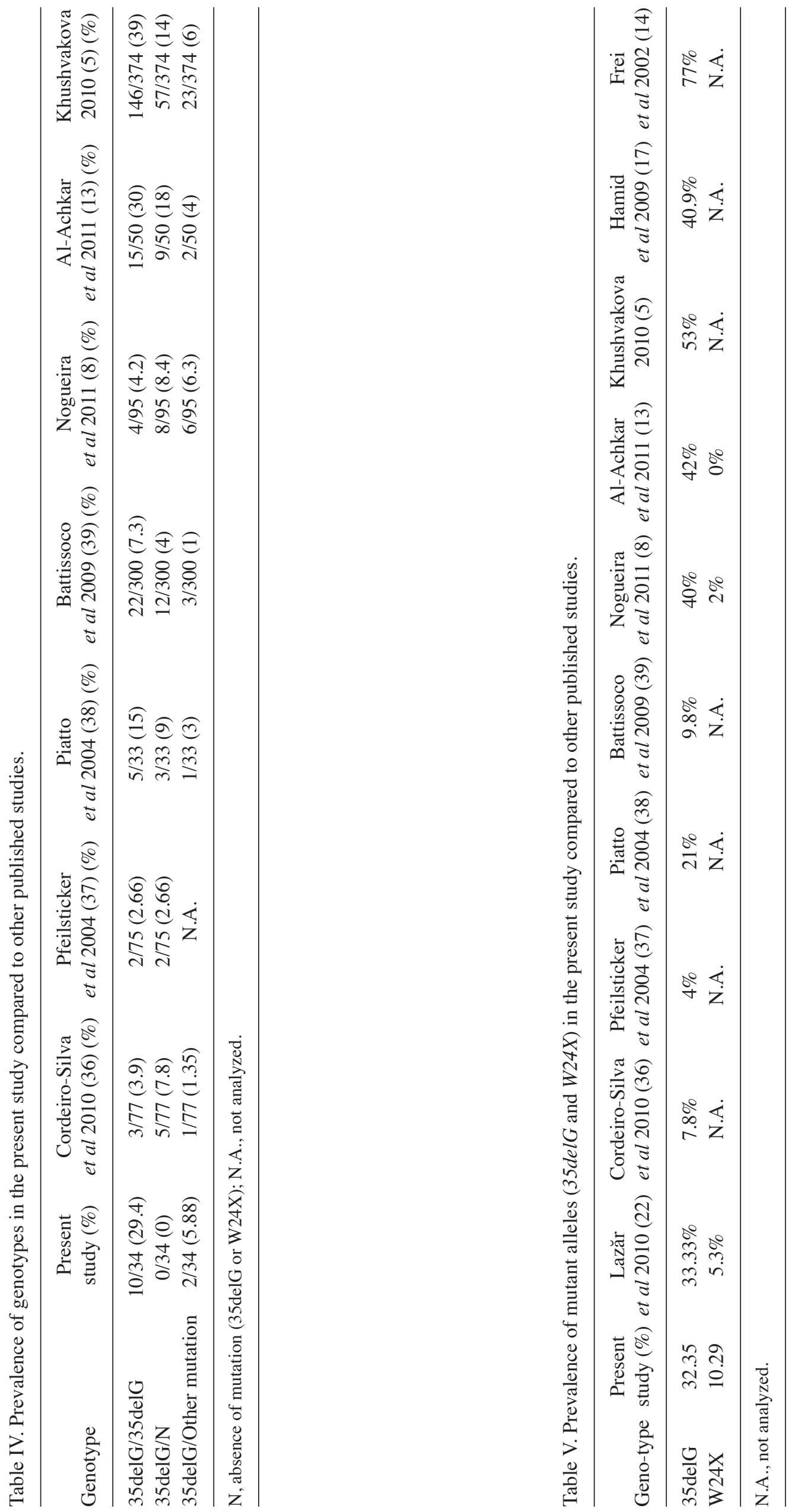
Table VI. Prevalence of genotypes in the present study compared to other published studies from Romania.

\begin{tabular}{lcccc}
\hline Genotype & Present study (\%) & Mocanu and Neagu 2013(23) & Totolin et al 2011 (24) & Lazăr et al 2010 (22) \\
\hline 35 delG/35delG & $10 / 34(29.4)$ & $30 / 84(36 \%)$ & $6 / 26(24 \%)$ & $19 / 75(25.33 \%)$ \\
$35 \mathrm{delG} / \mathrm{N}$ & $0 / 34(0)$ & $15 / 84(18 \%)$ & $5 / 26(19 \%)$ & $0 / 75(0 \%)$ \\
$\mathrm{N} / \mathrm{N}$ & $19 / 34(55.88)$ & $39 / 84(46 \%)$ & $15 / 26(57 \%)$ & $1 / 75(1.33 \%)$ \\
$\mathrm{W} 24 \mathrm{X} / \mathrm{W} 24 \mathrm{X}$ & $2 / 34(5.88)$ & N.A. & N.A. & $2 / 75(2.66 \%)$ \\
W24X/N & $1 / 34(2.94)$ & N.A. & N.A. & 2 \\
$35 \mathrm{delG} / \mathrm{W} 24 \mathrm{X}$ & $2 / 34(5.88)$ & N.A. & & \\
\hline
\end{tabular}

N.A., not analyzed.

Although genetic diagnosis is very expensive and is not routinely performed in developing countries, medical research can sometimes require a high degree of abstraction (31), and investigating the mutations of the GJB2 gene is essential in clarifying the problem of congenital hypoacusis. This type of diagnosis leads to genetic council for family members and facilitates the rapid rehabilitation of the child. The neuro-linguistic development of a newborn requires auditory stimulation within the first two years of life and deficits during this period are almost impossible to recover. For this reason, early diagnosis of a congenital hearing loss is of outmost importance. If such a diagnosis is possible, the children will be able to develop normal language and will no longer require special education $(32,33)$. The etiology of congenital SNHL entails environmental, clinical and genetic factors. Hearing disorders also were significantly associated with the presence of maternal pathologies but not with other prenatal or environmental factors such as radiation, or use of illegal drugs $(34,35)$.

In summary, the genetic affliction of a child also brings social and psychological consequences on the family (concern for the child's wellbeing, stigmatization, guilt for passing the disease on to the child) which can affect the parent's capabilities of coping with the situation. After the birth of a deaf child, the parents do not usually know the etiology and most of them do not anticipate a genetic factor, especially without a suggestive family history.

The present study confirms the relatively high prevalence of the $35 \mathrm{del} G$ and $W 24 X$ mutations in cases of congenital non-syndromic severe of profound bilateral SNHL, in accordance with previously published studies. Two of the patients presented a double mutation $35 \mathrm{delG} / \mathrm{W} 24 \mathrm{X}$ (bigenic heterozygosity). These results confirm the importance of genetic testing in clarifying the etiology and implementing a precocious recovery program for the patient. The purpose of such a program is optimal hearing and linguistic rehabilitation. The prevalence of the $35 \mathrm{del} G$ mutation within the European population also suggests the necessity of genetic screening which would facilitate the early identification of mutation carriers and would lead to genetic council accordingly.

Although genetic etiology is confirmed, the involvement of other environmental and clinical risk factors cannot be always ruled out. A clinician must always bear in mind that the reverse situation is even more common and complicated; the patients with suggestive risk factors (ototoxic treatments, hypoxia at birth, and prematurity) do not exclude a genetic etiology of the SNHL.

\section{Acknowledgements}

Not applicable.

\section{Funding}

No funding was received.

\section{Availability of data and materials}

Not applicable.

\section{Authors' contributions}

$\mathrm{HM}$ and AN contributed in all the stages of the article, they designed the article and revised the manuscript for important scientific content. AIM, AB and GC acquired the data, managed testing and evaluation and provided data analysis. HM and AIM also contributed to the conception of the work and revised the language. All authors read and approved the final manuscript.

\section{Ethics approval and consent to participate}

For this study, the agreement was obtained from the Research Ethics Committee of the Faculty of Medicine, Titu Maiorescu University (Romania). For any patients that required PCR testing written consent was obtained and beneficiated from anonymity by code designation.

\section{Patient consent for publication}

All patients provided informed consent and approved the publication of data.

\section{Competing interests}

The authors declare that they have no competing interests.

\section{References}

1. Bork J, Peters L and Riazuddin S: Genetic and metabolic hearing disorders. Am J Hum Genet 68: 26-37, 2001. 
2. Bitner-Glindzicz M: Hereditary deafness and phenotyping in humans. Br Med Bull 63: 73-94, 2002.

3. Petersen $\mathrm{M}$ and Willems P: Non-syndromic, autosomal-recessive deafness. Clin Genet 69: 371-392, 2006.

4. Markova T, Shagina I and Megrelishvilli: DNK-diagnostics congenital and early childhood hearing loss and deafness. Bull Otorhinolaryngol 6: 12-15, 2002.

5. Khushvakova N: Clinical and molecular genetic investigation of non-syndromic hearing disorders in children of the Uzbek population. MHSJ 2: 18-21, 2010.

6. Palmer CGS, Lueddeke JT and Zhou J: Factors influencing parental decision about genetics evaluation for their deaf or hard-of-hearing child. Genet Med 11: 248-255, 2009.

7. Shearer AE, Hildebrand MS, Smith RJH. Hereditary Hearing Loss and Deafness Overview. In: GeneReviews ${ }^{\circledR}$ [Internet] Adam MP, Ardinger HH, Pagon RA, Wallace SE, Bean LJH, Mirzaa $\mathrm{G}$ and Amemiya A(eds). University of Washington, Seattle, WA, 1993-2021.

8. Nogueira C, Coutinho M, Pereira C, Tessa A, Santorelli FM and Vilarinho L: Molecular investigation of pediatric Portuguese patients with sensorineural hearing loss. Genet Res Int 2011: 587602, 2011.

9. Zelante L, Gasparini P, Estivill X, Melchionda S, D'Agruma L, Govea N, Milá M, Monica MD, Lutfi J, Shohat M, et al: Connexin26 mutations associated with the most common form of non-syndromic neurosensory autosomal recessive deafness (DFNB1) in Mediterraneans. Hum Mol Genet 6: 1605-1609, 1997.

10. Fuse Z, Doi K, Hasegawa T, Sugii A, Hibino H and Kubo T: Three novel connexin 26 gene mutations in autosomal recessive nonsyndromic deafness. Neuroreport 10: 1853-1857, 1999.

11. Grifa A, Wagner CA, D'Ambrosio L, Melchionda S, Bernardi F, Lopez-Bigas N, Rabionet R, Arbones M, Monica MD, Estivill X, et al: Mutations in GJB6 cause nonsyndromic autosomal dominant deafness at DFNA3 locus. Nat Genet 23: 16-18, 1999.

12. Boulay AC, del Castillo FJ, Giraudet F, Hamard G, Giaume C, Petit C, Avan P and Cohen-Salmon M: Hearing is normal without connexin30. J Neurosci 33: 430-434, 2013.

13. Al-AchkarW,Moassass F,Al-Halabi B and Al-Ablog A: Mutations of the Connexin26 gene in families with non-syndromic hearing loss. Mol Med Rep 4: 331-335, 2011.

14. Frei K, Szuhai K, Lucas T, Weipoltshammer K, Schofer C, Ramsebner R, Baumgartner WD, Raap AK, Bittner R, Wachtler FJ and Kirschhofer K: Connexin 26 mutations in cases of sensorineural deafness in eastern Austria. Eur J Hum Genet 10: 427-432, 2002

15. Gasparini P, Rabionet R, Barbujani G, Melçhionda S, Petersen M Brøndum-Nielsen K, Metspalu A, Oitmaa E, Pisano M, Fortina $\mathrm{P}$, et al: High carrier frequency of the 35 delG deafness mutation in European populations. Eur J Hum Genet 8: 19-23, 2000.

16. Worldwide survey of the delta F508 mutation: Report from the cystic fibrosis genetic analysis consortium. Am J Hum Genet 47: 354-359, 1990

17. Hamid M, Karimipoor M, Chaleshtori MH and Akbari MT: A novel 355-357delGAG mutation and frequency of connexin-26 (GJB2) mutations in Iranian patients. J Genet 88: 359-362, 2009

18. Shahin H, Walsh T, Sobe T, Lynch E, King MC, Avraham KB and Kanaan M: Genetics of congenital deafness in the Palestinian population: Multiple connexin 26 alleles with shared origins in the Middle East. Hum Genet 110: 284-289, 2002.

19. Mustafa MWM: Prevalence of the connexin 26 mutation $35 \mathrm{delG}$ in non-syndromic hearing loss in Egypt. The Internet J Otorhinolar 3: No. 1, 2004

20. Chaleshtori MH, Rad LH, Dolati M, Sasanfar R, Pourjafari H, Ghadami $M$ and Farhud D: Frequencies of mutations in the connexin 26 gene (GJB2) in two populations of Iran (Tehran and Tabriz). Iranian J Publ Health 34: 1-7, 2005.

21. Wilcox SA, Osborn AH and Dahl HH: Simple PCR test to detect the common 35delG mutation in the connexin 26 gene. Mol Diagn 5: 75-78, 2000.

22. Lazăr C, Popp R, Trifa A, Mocanu C, Mihut G, Al-Khzouz C, Tomescu E, Figan I and Grigorescu-Sido P: Prevalence of the c. $35 \mathrm{delG}$ and $\mathrm{pW} 24 \mathrm{X}$ mutations in the GJB2 gene in patients with nonsyndromic hearing loss from North-West Romania. Int J Pediatr Otorhinolaryngol 74: 351-355, 2010.
23. Mocanu $\mathrm{H}$ and Neagu A: Prevalence of 35 delG and W24X mutations in non-syndromic congenital hearing loss. ORL.ro 28: $18-21,2015$

24. Totolin M, Boborelu G, Ioniţă E and Mitroi M: Prevalence of 35delG/GJB2 mutation in children with congenital nonsyndromic sensorineural hearing loss in Oltenia (South-Western Romania). Arch Balk Med Union 48: 177-181, 2013.

25. Maheswari M, Vijaya R, Ghosh M, Shastri S, Kabra M and Menon PS: Screening of families with autosomal recessive nonsyndromic hearing impairment (ARNSHI) for mutations in GJB2 gene. Indian Scenario. Am J Med Genet 120: 180-184, 2003.

26. RamShankar M, Girirajan S, Dagan O, Ravi Shankar HM, Jalvi R, Rangasayee R, Avraham KB and Anand A: Contribution of connexin26 (GJB2) mutations and founder effect to non-syndromic hearing loss in India. J Med Genet 40: e68, 2003.

27. Duncan RD, Prucka S, Wiatrak BJ, Smith RJH and Robin NH: Pediatric otolaryngologists' use of genetic testing. Arch Otolaryngol Head Neck Surg 133: 231-236, 2007.

28. Pandya A, Arnos KS, Xia XJ, Welch KO, Blanton SH, Friedman TB, Garcia Sanchez G, Liu MD XZ, Morell R and Nance WE: Frequency and distribution of GJB2 (connexin 26) and GJBG (connexin 30) mutations in a large North American repository of deaf probands. Genet Med 5: 295-303, 2003.

29. Schimmenti LA, Martinez A, Fox M, Crandall B, Shapiro N, Telatar M, Sininger Y, Grody WW and Palmer CG: Genetic testing as part of the early hearing detection and intervention (EHDI) process. Genet Med 6: 521-5, 2004

30. Withrow KA, Burton S, Arnos KA, Kalfoglou A and Pandya A: Consumer motivations for pursuing genetic testing and their preferences for the provision of genetic services for hearing loss. J Genet Couns 17: 252-260, 2008.

31. Alecu I, Mocanu H and Călin IE: Intellectual mobility in higher education system. Rom J Mil Med 120: 16-21, 2017.

32. Mocanu H: The role of perinatal hearing screening in the normal development of the infant's language. In: Debating Globalization. Identity, Nation and Dialogue. Boldea I and Sigmirean C (eds). 4th edition. Arhipeleag XXI Press, Tirgu Mures, pp562-569, 2017.

33. Mocanu $\mathrm{H}$ : The economic impact of early diagnosis of congenital hearing loss. In: Debating Globalization. Identity, Nation and Dialogue. Boldea I and Sigmirean C (eds). 4th edition. Arhipeleag XXI Press, Tirgu Mures, pp556-561, 2017.

34. Mocanu $\mathrm{H}$ and Oncioiu I: The influence of clinical and environmental risk factors in the etiology of congenital Sensorineural hearing loss in the Romanian population. Iran J Publ Health 48: 2301-2303, 2019

35. Neudert M, Bornitz M, Mocanu H, Lasurashvili N, Beleites T, Offergeld $\mathrm{C}$ and Zahnert T: Feasibility study of a mechanical real-time feedback system for optimizing the sound transfer in the reconstructed middle ear. Otol Neurotol 39: e907-e920, 2018

36. Cordeiro-Silva MF, Barbosa A, Santiago M, Provetti M and Rabbi-Bortolini E: Prevalence of $35 \mathrm{delG} / \mathrm{GJB} 2$ and del (GJB6-D13S1830) mutations in patients with non-syndromic deafness from a population of Espírito Santo-Brazil. Braz J Otorhinolaryngol 76: 428-432, 2010 (In English, Portuguese).

37. Pfeilsticker LN, Stole G, Sartorato EL, Delfino D and Guerra ATM: A investigação genética na surdez hereditária não-sindrômica. Rev Bras Otorrinolaringol 70: 181-186, 2004.

38. Piatto VB, Bertollo EM, Sartorato EL and Maniglia JV: Prevalence of the GJB2 mutations and the del (GJB6-D13S1830) mutation in Brazilian patients with deafness. Hear Res 196: 87-93, 2004.

39. Batissoco AC, Abreu-Silva RS, Braga MC, Lezirovitz K, Della-Rosa V, Alfredo T Jr, Otto PA and Mingroni-Netto RC: Prevalence of GJB2 (connexin-26) and GJB6 (connexin-30) mutations in a cohort of 300 Brazilian hearing-impaired individuals: Implications for diagnosis and genetic counseling. Ear Hear 30: 1-7, 2009. 